TABLE III-Mean ( $\pm S E$ of mean) vital capacity in three groups of 15 patients given parenteral morphine sulphate after operation, expressed as percentage of preoperative value

\begin{tabular}{|c|c|c|c|}
\hline \multirow{2}{*}{$\begin{array}{l}\text { Time after } \\
\text { operation } \\
\text { (hours) }\end{array}$} & \multicolumn{3}{|c|}{ Group } \\
\hline & A & B & C \\
\hline $\begin{array}{l}12 \\
24 \\
36 \\
48 \\
60 \\
72\end{array}$ & $\begin{array}{c:c}29 \cdot 1 & 2 \cdot 8^{*} \\
42 \cdot 0 & 4 \cdot 1^{*} \\
43 \cdot 0 & 3 \cdot 9^{*} \\
50 \cdot 5 & 4 \cdot 2^{*} \\
55 \cdot 2 & 4 \cdot 2^{*} \\
60 \cdot 1 & 3 \cdot 8^{*}\end{array}$ & $\begin{array}{c:c}21 \cdot 0 & 1 \cdot 7 \\
33 \cdot 4 & 1 \cdot 6 \\
36 \cdot 1 & 1 \cdot 7 \\
41 \cdot 0 & 2 \cdot 7 \\
43 \cdot 1 & 2 \cdot 9 \\
52 \cdot 5 & 4 \cdot 1\end{array}$ & $\begin{array}{l:l}19 \cdot 7 & 1.6 \\
28.3 & 4 \cdot 1 \\
31 \cdot 2 & 2 \cdot 5 \\
37.2 & 3 \cdot 1 \\
41.0 & 2 \cdot 9 \\
50 \cdot 5 & 3.8\end{array}$ \\
\hline
\end{tabular}

*Significant difference from group C at $0.05 \mathrm{level}$ (Mann-Whitney U test).

$110 \mathrm{mg}$ ) of morphine during the 72 hours, while patients in group $\mathrm{C}$ received $80-280 \mathrm{mg}$ (mean $140 \mathrm{mg}$ ) indicating that difference in pain relief between the two groups was not due to the patients in group $\mathrm{C}$ experiencing difficulties or delay in obtaining morphine. By contrast, patients in group A received $28-63 \mathrm{mg}$ (mean $36 \mathrm{mg}$ ) of morphine over the 72 hours. Patients in group B did not require morphine in addition to their regular regimen, though this was freely available. Only one patient in group A required extra morphine (two doses of $10 \mathrm{mg}$ given intramuscularly). The titration doses in the trial had a modal value of $10 \mathrm{mg}$ (range $7.5-18 \mathrm{mg}$ ), and 25 patients received this dose.

\section{Discussion}

This trial shows that intravenous infusion of morphine gives better pain relief at a lower dosage than other regimens. In particular, when morphine was given as required relatively large amounts were given with little effect. Though we do not think that the improved vital capacity and peak expiratory flow rate obtained with continuous infusion are anything more than objective measures of pain relief, it is interesting that pulmonary complications (as judged by clinical and radiological findings) occurred significantly more often in patients in groups B and C than in those in group A $(\mathbf{P}=0.032$, Fisher's exact test with Tocher's modification ${ }^{6}$ ); statistical analysis must, however, be applied cautiously to such data.

We do not suggest that continuous intravenous infusion of morphine is the optimum method of postoperative sedation, only that when morphine (or one of its analogues) is given, continuous intravenous infusion should be the method of choice. Though accidental overdosage from an inadequately controlled pump did not occur in this study, it is always possible, and it is best avoided by prescribing a standard dose in a standard volume administered by a pump with a single-speed motor. Variations in dosage are then only achieved by changing the motor drive.

\section{References}

${ }^{1}$ Fry EM. Postoperative pain. Br Med $\mathcal{f} 1976 ; 2: 817$.

2 Leading article. Postoperative pain. Br Med f 1976;2:664.

${ }^{3}$ Stapleton JV, Austin KL, Mather LE. Postoperative pain. $\mathrm{Br} \mathrm{Med} f$ $1978 ; 2: 1499$

- Church JJ. Continuous narcotic infusions for relief of postoperative pain. Br Med f 1979;1:977-9.

${ }^{5}$ Revill SI, Robinson JO, Rosen M, Hogg MI. The reliability of a linear analogue for evaluating pain. Anaesthesia $1976 ; 31: 1191-8$.

' Siegel S. Non-parametric statistics for the behavioural sciences. Tokyo: McGraw-Hill, 1956.

\title{
Standard exercise test to assess peripheral arterial disease
}

\author{
SUSAN P LAING， ROGER M GREENHALGH
}

\section{Summary and conclusions}

The fall in ankle systolic pressure after exercise serves as an objective indicator of the severity of haemodynamically important peripheral arterial disease. Twenty-six patients were studied to establish the effects of different work loads on the pressure response and to develop a test to standardise these effects. The patients walked for one or two minutes at $4 \mathrm{~km} / \mathrm{h}$ and one or two minutes at $6 \mathrm{~km} / \mathrm{h}$, and the fall in pressure was the same when measured immediately after exercise. The time taken for the pressure to return to the pre-exercise value varied.

As the fall in pressure occurs after only one minute of exercise at $4 \mathrm{~km} / \mathrm{h}$ on a $10 \%$ slope, this might be adopted as a standard test. It is acceptable to the patient, since claudication, angina, and shortness of breath rarely occur. It is sensitive enough to detect mild or asymptomatic disease and is useful in following up patients.

Charing Cross Hospital, London W6 8RF

SUSAN P LAING, BA, research assistant

ROGER M GREENHALGH, MCHIR, FRCs, senior lecturer in surgery and honorary consultant surgeon

\section{Introduction}

The pressure measured at the ankle with a pressure cuff and Doppler probe is an indirect measure of the arterial systolic pressure. The pressure may also be measured similarly at the calf and thigh. Although the absolute ankle pressure is important in some cases (for example, before selecting the site of an amputation), the pressure index is most widely used. This is the ratio of the ankle to the brachial pressure and in a normal healthy subject is approximately 1 . A pressure index below 0.9 indicates appreciable arterial disease.

The ankle systolic pressure and pressure index are reliable and accurate measurements. The pressure index has a day-to-day coefficient of variation of $6.4^{\circ}, 0$ in this laboratory. These measurements reflect the severity of the disease and can distinguish between single and multiple stenoses but cannot be used to predict the site of the disease. For example, an aortoiliac stenosis cannot be distinguished from a femoropopliteal stenosis by the pressure index alone. A further criticism of resting tests is that they do not measure the functional changes in blood flow that occur during exercise. Therefore, vascular laboratories commonly incorporate an exercise test when evaluating patients with intermittent claudication. ${ }^{12}$ The tests most commonly used are measurements of the claudication distance as the patient walks on a treadmill and of the ankle systolic pressure before and after a period of exercise.

The claudication distance (the point of onset of claudication, measured from the time the patient starts to walk) is an assessment of the disability of the patient but is subjective, may 
fluctuate considerably between visits, ${ }^{3}$ and does not correlate well with any objective measurement. ${ }^{1}{ }^{4}$ Furthermore, it applies to only the most severely diseased limb, and thus claudication in one limb may "mask" the development of symptoms in the other, less affected limb. With this type of test the patient is apt to push himself to his limits and may also suffer from shortness of breath or angina. The ankle pressurc after exercise is a sensitive and objective assessment of haemodynamically important disease and thus has advantages over the claudication distance alone. The response to exercise is related to the severity of disease ${ }^{5}$ and the degree of development of collateral arteries, but if this test is to be used repeatedly to assess discase it is important to ascertain how other parameters affect the response
Group II-The results in this group were similar to those obtained in group I. There was an extended recovery period for the longer period of exercise (fig 2).

Group III-The effect of different amounts of exercise on the pressure response was clearly evident in this group. There was no difference in the mean pressures before or immediately after the exercise tests, but there was a significant difference during the recovery period $(P<0 \cdot() 1)$. The mean recovery time for the walk at one minute at $4 \mathrm{~km} / \mathrm{h}$ was five minutes, and for the walk at two minutes at $6 \mathrm{~km} \mathrm{~h} 12$ minutes (fig 3).

Within this range of exercise quotas, for any given ankle pressure before exercise, the pressure fell to the same value however far or fast the patient walked. The recovery time was extended with an increased work load.

Mean $( \pm S E)$ ankle pressures $(m m H g)$ before and after exercise in each group studied

\begin{tabular}{|c|c|c|c|c|c|c|c|}
\hline \multirow{2}{*}{$\begin{array}{c}\text { Duration } \\
\text { of } \\
\text { exercise }\end{array}$} & \multirow{2}{*}{$\begin{array}{c}\text { Rate } \\
(\mathrm{km} / \mathrm{h})\end{array}$} & \multicolumn{2}{|c|}{ Before exercise } & \multicolumn{2}{|c|}{$40 \mathrm{~s}$ after exercise } & \multicolumn{2}{|c|}{$100 \mathrm{~s}$ after exercise } \\
\hline & & Pressure & Significance & Pressure & Significance & Pressure & Significance \\
\hline \multicolumn{8}{|c|}{ Group I (20 limbs) } \\
\hline 1 min & $\begin{array}{l}4 \\
6\end{array}$ & $\left.\begin{array}{l}118 \cdot 7: 4 \cdot 8 \\
115 \cdot 7\end{array} 5 \cdot 2\right\}$ & NS & $\begin{array}{l}58 \cdot 3: 5 \cdot 1 \\
55 \cdot 3: 3 \cdot 9\end{array}$ & NS & $\begin{array}{l}89 \cdot 2: 9 \cdot 1 \\
70 \cdot 1: 8 \cdot 1\end{array}$ & \}$P \cdot 0.001$ \\
\hline \multicolumn{8}{|c|}{ Group II (20 limbs) } \\
\hline $\begin{array}{l}1 \mathrm{~min} \\
2 \mathrm{~min}\end{array}$ & $\begin{array}{l}4 \\
4\end{array}$ & $\left.\begin{array}{l}121 \cdot 6: 4 \cdot 9 \\
119 \cdot 5: 5 \cdot 5\end{array}\right\}$ & $\mathrm{NS}$ & $\begin{array}{l}57 \cdot 6: 4 \cdot 4 \\
58 \cdot 0: 4 \cdot 3\end{array}$ & NS & $\begin{array}{l}106: 9 \cdot 2 \\
82 \cdot 2: 8 \cdot 8\end{array}$ & \}$P \cdot 0.01$ \\
\hline \multicolumn{8}{|c|}{ Group III (10 limbs) } \\
\hline $2 \mathrm{~min}$ & 6 & $116.9: 5.9\}$ & NS & $55 \cdot 8: 4 \cdot 1$ & NS & $62 \cdot 8: 7 \cdot 7$ & P. 0.01 \\
\hline
\end{tabular}

NS $=$ Not significant

of the ankle pressure to exercise. If the patient is exercised to the point of claudication before the ankle pressure is measured the distance and thus the work load will fluctuate from visit to visit.

We performed this study to establish the effect of different work loads on the ankle-pressure response and to develop a standard exercise test to eliminate this variable.

\section{Patients and methods}

We studied 26 patients with peripheral arterial disease, who all presented with intermittent claudication. The patients were rested for 10 minutes, after which the arm and ankle systolic pressures were measured using a Doppler probe and pressure cuff as described elsewhere." After a period of exercise on a treadmill the patient returned to the bed. The ankle pressure was measured immediately and subsequently at one-minute intervals until it returned to the preexercise level. Between each test the patient was rested for a further 10 minutes. The pressure response to exercise was plotted as a graph.

The patients were divided into three groups to study the effect of different quotas of exercise on the ankle-pressure response. All the patients walked for a period of one minute at $4 \mathrm{~km} \mathrm{~h}$ on a 10 incline.

Group $I$ (19 patients)-The effect of increasing the rate of walking was examined in 20 limbs. The additional exercise test was for one minute at $6 \mathrm{~km} / \mathrm{h}$.

Group II (17 patients)-The effect of increasing the distance walked was examined in 20 limbs. The additional exercise test was for two minutes at $4 \mathrm{~km} / \mathrm{h}$

Group III (10 patients)-Patients in this group were also included in groups $I$ and II. The cumulative effect of increasing the rate and the distance was examined in 10 limbs. The additional exercise test was for two minutes at $6 \mathrm{~km} / \mathrm{h}$.

\section{Results}

The mean response of the limbs in each group to the different exercise quotas was calculated. A paired Student's $t$ test was used to compare the mean pressure before exercise, immediately after exercise, and at one-minute intervals during the recovery period (table).

Group I-The mean ankle pressure was the same before each exercise test. Immediately after each test the pressure fell to the same point, but by one minute after this measurement the pressures were significantly different $(\mathrm{P}<0.001)$, indicating an extended recovery period for the walk at the faster speed (fig 1).

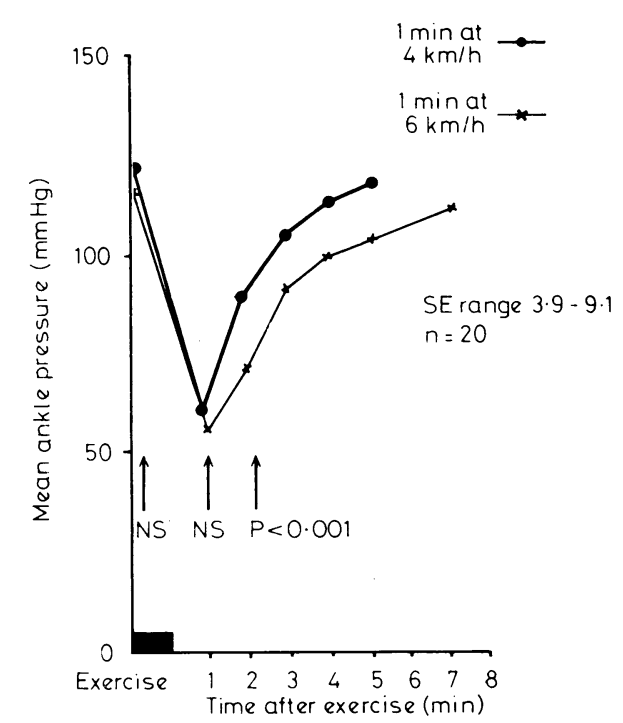

FIG 1 -Mean ankle-pressure response in patients in group after exercise for one minute at $4 \mathrm{~km} / \mathrm{h}$ and one minute at $6 \mathrm{~km} / \mathrm{h}$.

NS - Not significant.

\section{Discussion}

Functionally important peripheral arterial disease is shown by a fall in ankle systolic pressure after exercise. The ankle pressure subsequently returns to the pre-exercise value. In cases of severe occlusive disease the ankle pressure at rest will be lower than the brachial pressure and proportional to the resistance of the diseased vessels and collateral arteries. In all cases of haemodynamically important disease the pressure after exercise is reduced even more in proportion to the velocity of blood flow across the stenosis as the resistance in the muscle mass is lowered. Furthermore, blood appears to be shunted away from the distal arteries to the exercising muscles. ${ }^{6}$;

When a healthy subject is exercised within the range used in this study the ankle pressure will remain the same or be slightly increased.' Severe exercise, however, even in a normal patient, 
may produce a fall in pressure. Again, this is apparently due to the decrease in resistance to flow in the exercising muscles and thus the shunting of blood away from the distal arteries to these areas. In a patient with peripheral arterial disease exercise testing within this range will cause the ankle pressure to fall to the same point for any given pressure before exercise. The

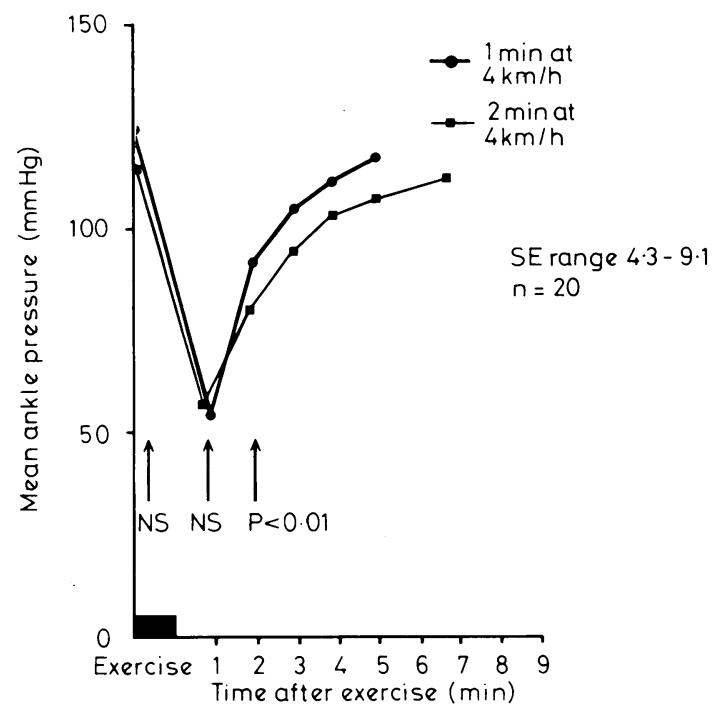

FIG 2-Mean ankle-pressure response in patients in group II after exercise for one minute at $4 \mathrm{~km} \mathrm{~h}$ and two minutes at $4 \mathrm{~km}$ h.

NS Not significant.

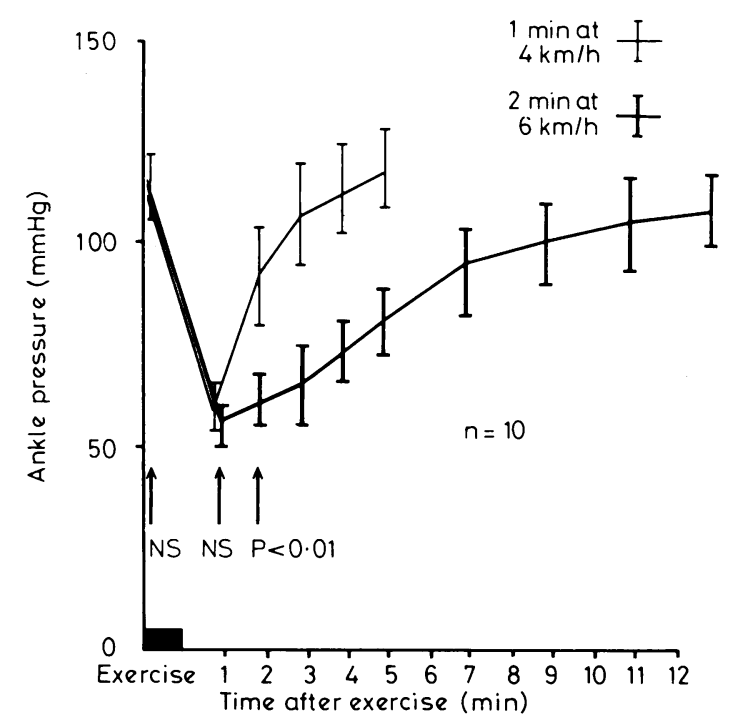

FIG $3-$ Mean $\pm \mathrm{SE}$ ankle-pressure response in patients in group III after exercise for one minute at $4 \mathrm{~km} / \mathrm{h}$ and two minutes at $6 \mathrm{~km} \mathrm{~h}$.

NS $=$ Not significant.

blood-flow response in all patients is related to the amount of work performed until a maximum flow is reached. In patients with peripheral arterial disease the peak flow is reached at low work levels. ${ }^{9}$ The constant point to which the pressure falls is also reached after low work levels. The extended recovery time, related to the period of hyperaemia after exercise, varies with the work load.

These results apparently contradict those of Skinner and Strandness. " They studied the effect of different walking times on the ankle-pressure response to exercise in four patients. They showed that a greater work load resulted in a greater fall in pressure and an extended period of hyperaemia after exercise.
The apparent discrepancy might be because the ankle pressure was not measured until two minutes after exercise. Our study showed that by this time the difference in recovery rates for different exercise quotas is already evident.

The ankle systolic pressure after exercise is related to the severity of the disease." The pressure fall is the same whatever the period of exercise. Thus it is not necessary to exercise the patient until the onset of pain. Exercise for one minute is sufficient to achieve this pressure drop, and we have now standardised the test to one minute at $4 \mathrm{~km} / \mathrm{h}$ on a $10^{\circ}$ incline. The sensitivity of the test to mild disease is not diminished by standardising it to only one minute, but as the recovery period is likely to be rapid it is essential that a measurement is taken immediately after exercise. The walking test is performed twice, so that the pressure in each limb may be measured separately. If the patient cannot walk for one minute the exercise quota may be standardised according to his abilities.

This test is acceptable to both patient and doctor. The patient is no longer exercised to the point of claudication, and the concomitant problems of shortness of breath and angina rarely occur during this short period. The test is quick and easy to perform. It provides quantitative information that helps the doctor in differentially diagnosing disease and selecting patients for arteriography and surgery, thus reducing the incidence of unnecessary arteriography. For example, symptoms may be neurogenic or vascular in origin. Showing that the physiological function of the arterial system is normal at rest and in response to exercise eliminates arterial disease as a cause.

The claudication distance is a subjective measure of the disability of only the most severely diseased limb, whereas the standard exercise test permits an objective assessment of the severity of disease in both limbs. This permits a preoperative prediction of the degree of residual disability in an apparently asymptomatic limb, which would remain if the flow to only the more severely diseased limb was improved. The decision whether to carry out a unilateral or bilateral operation is aided by this information.

The ankle-pressure response to exercise is a sensitive test of haemodynamically important disease. In patients with mild symptoms the ankle pressure may be normal at rest and an abnormality will be detected only by a fall in pressure after exercise. Thus, while it is appropriate for a patient with rest pain to undergo an objective assessment at rest, it is appropriate for a patient with intermittent claudication to undergo an objective assessment after exercise. By using this test in a preliminary study in the follow-up clinic we found that out of 58 apparently asymptomatic limbs, $26\left(45^{\circ}{ }_{0}\right)$ were functionally abnormal, whereas only eight $\left(14^{\circ}{ }_{10}\right)$ were found to be functionally abnormal by measurements of resting pressure alone. Thus the test may be used to screen for asymptomatic but functionally important disease at an early stage.

This standard test is of most use in the follow-up clinic, where regular arteriography would be inappropriate. Progression of disease or an improvement in the collateral circulation from one visit to the next will be reflected by a changing pressure response to exercise, but this will also be affected by a variable work load. Standardising the test eliminates this variable. This test is row being used to detect progression of disease and to predict graft failure before the patient develops symptoms or any change has occurred in clinical findings. This sensitivity of assessment has not been available before using this equipment.

Requests for reprints should be sent to RMG.

\section{References}

${ }^{1}$ Yao ST, Needham TI, Gourmos C, Irvine WT. A comparative study of strain-gauge plethysmography and Doppler ultrasound in the assessment of occlusive disease of the lower extremities. Surgery 1972;71:4-9.

2 Fronek A, Coel M, Bernstein EF. The importance of combined multisegmental pressure and Doppler flow velocity studies in the diagnosis of peripheral arterial occlusive disease. Surgery 1978;84:840-7. 
${ }^{3}$ Hillestad LK. The peripheral blood flow in intermittent claudication. IV. The significance of the claudication distance. Acta Med Scand 1963;173 467-78.

4 Lorentsen E. Blood pressure and flow in the calf in relation to claudication distance. Scand 7 Clin Lab Invest 1973;31:141-6.

5 Yao ST. New techniques in objective arterial evaluation. Arch Surg 1973; $106: 600-4$.

${ }^{6}$ Sumner DS, Strandness DE. The relationship between calf blood flow and ankle pressure in patients with intermittent claudication. Surgery 1965 ; $65: 763-71$.

; Strandness DE, Bell JW. An evaluation of the haemodynamic response of the claudicating extremity to exercise. Surg Gynecol Obstet 1964;119: 1237-42.

* Stahler C, Strandness DE. Ankle blood pressure response to graded treadmill exercise. Angiology 1967;18:237-41.

${ }^{9}$ Folse R. Alterations in femoral blood flow and resistance during rhythmic exercise and sustained muscular contractions in patients with arteriosclerosis. Surg Gynecol Obstet 1965;121:767-76.

10 Skinner JS, Strandness DE. Exercise and intermittent claudication. Effect of repetition and intensity of exercise. Circulation 1967;36:15-22.

(Accepted 5 October 1979)

\title{
Asthma induced by enkephalin
}

\author{
R D G LESLIE，DAVID BELLAMY，DAVID A PYKE
}

\section{Summary and conclusions}

A total of 291 diabetics were studied to see whether an asthmatic reaction was associated with facial flushing induced by chlorpropamide and alcohol. Of these patients, 191 reported facial flushing, of whom 12 reported breathlessness as well. Of these 12 , five also described wheezing, and respiratory function tests showed them to have asthma. Three of these five patients underwent further tests, which showed that the asthmatic reaction could be prevented by giving disodium cromoglycate and the specific opiate antagonist naloxone. One patient developed wheezing when given an enkephalin analogue with opiate-like activity.

Asthma induced by chlorpropamide and alcohol was concluded to be mediated by endogenous peptides with opiate-like activity such as enkephalin.

\section{Introduction}

Facial flushing after alcohol is well recognised in diabetics receiving chlorpropamide. Occasionally patients report breathlessness and even wheezing during chlorpropamide-alcohol flushing (CPAF). ${ }^{1}$ We investigated the incidence and nature of this reaction and have shown that CPAF is caused by increased sensitivity to endogenous opiates such as enkephalin, a pentapeptide with opiate-like activity. ${ }^{3}$ We therefore carried out a study to determine whether enkephalin was the cause of wheezing in these patients. We attempted to block the wheezing with the specific opiate antagonist naloxone and to induce it by infusing the enkephalin analogue ( $H$-Tyr-D-Ala-Gly-MePheMet (O)-ol)-enkephalin (DAMME, Sandoz).

\section{Patients and methods}

We asked 291 diabetics taking chlorpropamide to describe any symptoms after drinking $40 \mathrm{ml}$ sherry in one minute. Any patients who described wheezing and CPAF during this test were then asked to perform a series of alcohol challenge tests. The tests, which were performed on separate days after bronchodilator treatment had been stopped for at least 12 hours, were as follows: (1) 12 hours after

Diabetic Department and Chest Unit, King's College Hospital, London SE5 9RS

R D G LESLIE, MRCP, research fellow

DAVID BELLAMY, MRCP, senior medical registrar

DAVID A PYKE, FRCP, consultant physician taking $250 \mathrm{mg}$ chlorpropamide patients drank $100 \mathrm{ml}$ sherry over five minutes ; (2) 20 minutes before drinking sherry as above patients inhaled $20 \mathrm{mg}$ disodium cromoglycate; (3) 12 hours after taking $250 \mathrm{mg}$ chlor-

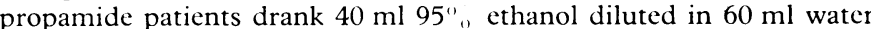
(about equivalent to the sherry's ethanol concentration) over five minutes; (4) 12 hours after taking $250 \mathrm{mg}$ chlorpropamide patients inhaled $5 \mathrm{ml} \mathrm{10"} \mathrm{"ethanol} \mathrm{in} \mathrm{physiological} \mathrm{saline;} \mathrm{and} \mathrm{(5)} 12$ hours after taking $5 \mathrm{mg}$ glipizide patients drank $100 \mathrm{ml}$ sherry over five minutes.

Three baseline measurements of forced expiratory volume in one second $\left(\mathrm{FEV}_{1}\right)$ and slow vital capacity (VC) were made with a Vitalograph before the challenge tests and then at five-minute intervals for 15 minutes and at 15-minute intervals for 75 minutes after the alcohol had been administered. Blood samples were taken in test 1 via an indwelling venous cannula 10 minutes before and at $0,5,10$, 20,30 , and 60 minutes after the patient had finished the sherry to determine total IgE concentration, absolute cosinophil count, and serotonin concentration. IgE concentration was measured by solidphase radioimmunoassay and serotonin assayed on whole blood fluorometrically. ${ }^{4}$

Naloxone block of asthma-Two patients (cases 1 and 2) received naloxone $0.4 \mathrm{mg} / \mathrm{min}$ and on another occasion saline infused through an indwelling venous cannula. The infusion began five minutes before test 1 and continued for 20 minutes thereafter.

Infusion of enkephalin analogue-Two patients who exhibited CPAF (one who reported concomitant wheezing (case 1) and one who did not (case 4)) were given an intravenous infusion of $0.25 \mathrm{mg}$ of the enkephalin analogue DAMME over two minutes. They had taken no chlorpropamide for two months and no other drugs for 48 hours before the infusion. Measurements of $\mathrm{FEV}_{1}$ and slow VC were made with a Vitalograph.

\section{Results}

Of the 291 diabetics studied, 191 reported facial flushing after chlorpropamide and alcohol. Twelve patients described breathlessness accompanying the CPAF, of whom five also wheezed; respiratory function tests showed these five patients to have asthma. Two patients known to have asthma and who showed CPAF, however, did not report any respiratory symptoms during the flush and their FEV did not change after challenge with chlorpropamide and alcohol.

Of the five patients who described wheezing during CPAF, three agreed to undergo the series of alcohol challenge tests. Their case histories are given below.

Case 1-This 55-year-old man had experienced mild productive cough during the previous winter but denied any wheezing or history of asthma. There was no family history of atopy or asthma. He did not smoke. Clinical examination, chest radiography, and blood count showed no abnormalities. Skin-prick tests with various common allergens gave negative result. Results of pulmonary function tests were: $\mathrm{FEV}_{1}$ increased from $2 \cdot 01$ to $2 \cdot 21$ after two puffs of salbutamol (predicted value $2.4 \mathrm{l}$ ); VC increased from 2.71 to $2.9 \mathrm{l}$ after salbutamol (predicted value $3.0 \mathrm{l}$ ); and carbon monoxide pulmonary diffusing capacity $(\mathrm{D}, \mathrm{CO})$ (single breath) was $8 \mathrm{mmol} / \mathrm{min} / \mathrm{kPa}(24 \mathrm{ml} / \mathrm{min} /$ 